\title{
Can Early Clinical Status Predict Outcomes in Extremely Low Birth Weight Neonates?
}

\author{
Alok Kumar MK ${ }^{1}$ Femitha Pournami ${ }^{1}$ Sujith Kumar Reddy Gurram Venkata ${ }^{1} \quad$ Anand Nandakumar ${ }^{1}$ \\ Jyothi Prabhakar ${ }^{1}$ Naveen Jain ${ }^{1}$
}

${ }^{1}$ Department of Neonatology, Kerala Institute of Medical Sciences, Trivandrum, Kerala, India

J Child Sci 2020;10:e32-e37.

\author{
Abstract \\ Keywords \\ - extremely low birth \\ weight \\ - infant \\ - extremely premature \\ - patient relevant \\ outcome \\ - bronchopulmonary \\ dysplasia \\ - mortality
}

Address for correspondence Femitha Pournami, DM, Department of Neonatology, Kerala Institute of Medical Sciences, Trivandrum 695029, Kerala, India (e-mail: femi_shifas@yahoo.com).

Background Extremely low birth weight (ELBW) neonates are the sickest patrons of neonatal intensive care. Authors have attempted to predict outcomes based on perinatal factors very soon after birth. Allowing a longer duration for clinical assessment may permit meaningful assessments. Postponing these predictions to several weeks does not offer succour.

Methods We retrospectively studied association of predefined perinatal factors and clinical status of 53 ELBW infants in the first 72 hours of life; with death or continued need for respiratory support at 4 weeks of life separately (RS4).

Results Mean and standard deviations of birth weight and gestational age were 781.8 $( \pm 130.7) \mathrm{g}$ (range: $510-990 \mathrm{~g})$ and 26.4 ( \pm 1.5$)$ weeks (range: $24-30$ weeks), respectively; $32.9 \%$ were $<750 \mathrm{~g}$ at birth. Of the 53 neonates, $20.7 \%$ babies expired and $47.1 \%$ required RS4 (66\% neonates suffered composite outcome of death/RS4). Need for $>0.3$ fraction of inspired oxygen $\left(\mathrm{FiO}_{2}\right)$ beyond 72 hours of life demonstrated strong association with death/RS4 (odds ratio [OR] 14.3; 95\% confidence interval [CI] 3.2-63.0). Need for chest compression (OR 15.3; 95\% $\mathrm{Cl} 1.4-167.2$ ) and shock (OR 14.2; $95 \% \mathrm{Cl} 2.7-72.8$ ) were significantly associated with mortality.

Conclusion $\mathrm{FiO}_{2}$ requirement of $>0.3$ at 72 hours reasonably predicts death or dependence on respiratory supports at 4 weeks of life.

\section{Introduction}

Extremely low birth weight (ELBW) neonates are often the sickest patients in neonatal intensive care facilities. Parents are anxious and physicians are often left with the daunting task of counseling about likely outcomes. Previous authors have attempted to predict outcomes very soon after birth, based on perinatal factors. ${ }^{1,2}$ However, predicting outcomes without allowing the infant reasonable time on intensive care support may make things look unrealistically dismal. Allowing a slightly longer duration on standard care for clinical assessment and judgment may permit more meaningful assessments. This approach has been recommended in prominent guidelines. ${ }^{3}$ The problems in the immediate postnatal period in an ELBW baby have many facets that form a complex mosaic. All of these may affect outcomes. Nevertheless, postponing these predictions to several weeks postnatal also does not offer succour to already stressed families. ${ }^{4}$

The most important outcome of interest would obviously be survival. Concurrently, need for prolonged respiratory supports would in turn influence length of stay and expenses to the family. ${ }^{5,6}$ Being able to envisage these possible outcomes may aid in parent counseling and help the clinical team plan resources as well. We hypothesized that composite outcomes of death or continued need for respiratory supports at 4 weeks received

March 27, 2020

accepted after revision

May 5, 2020
DOI https://doi.org/

10.1055/s-0040-1713659.

ISSN 2474-5871.
Copyright @ 2020 Georg Thieme Verlag License terms

KG Stuttgart · New York

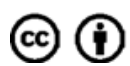


postnatal age (RS4), may be predicted by perinatal factors and clinical status in the first 3 days of life itself.

\section{Methodology}

This retrospective study was designed to analyze association of predefined perinatal factors and clinical status till 72 hours of life; with composite outcome of death or continued need for respiratory support at 4 weeks of life (RS4).

All babies (inborn; or outborn referred to the unit within 12 hours of birth) who were ELBW (birth weight $<1,000 \mathrm{~g}$ ), and who received intensive care support and completed care in the unit, during the period from January 2017 till April 2019 were included. We excluded those with major congenital malformations requiring surgery. Gestational age assessment is done using first trimester ultrasound scan, last menstrual period when menstrual cycles are regular, or Modified Ballard score ${ }^{7}$ postnatally in order of priority.

Ours is a 26-bedded Level IIIB accredited (National Neonatology Forum, India) unit in a teaching, referral, private sector hospital of South India. The unit follows a protocol of resuscitating any baby born $>23$ weeks $/ 400 \mathrm{~g}$ birth weight (even borderline viable babies), with signs of life at birth. ${ }^{3}$ They receive standard intensive care which involves neonatal resuscitation according to current guidelines. ${ }^{8}$ Respiratory supports are based on clinical and radiological status. ${ }^{9}$ The perinatal unit follows standard guidelines for antenatal care of threatened preterm labor, timing of delivery for maternal and fetal indications, and antenatal steroids. ${ }^{9}$ Antenatal magnesium sulfate for neuroprotection was not uniformly practiced in 2017 to 2018. Written protocols exist for care of extreme preterm neonates at birth, respiratory support, surfactant therapy, insertion of central lines, parenteral, and enteral nutrition. These supports are continued for at least 72 hours even if impulsive parent decisions are otherwise. Repeated discussions at frequent intervals are held to update families about the infant's clinical status. We practice early parent participation and allow unrestricted visitation to both parents. There are criteria for transition to step-down beds and for rooming in with mother after stabilization. Mother's own milk is promoted and extensive efforts are made to optimize availability. Those delivered at $<24$-week gestation or $\leq 400 \mathrm{~g}$, with signs of life at birth are shifted to the neonatal intensive care unit for comfort care which includes warmth and free-flow oxygen alone. If they are alive beyond 1 hour of life, they receive intravenous fluids by peripheral cannula.

A convenience sample of preterm neonates satisfying inclusion criteria over a period of 28 months was taken. The data on perinatal risk factors (gestational age, birth weight, antenatal steroids, maternal chorioamnionitis, gender, multiple gestation, abnormal umbilical artery Doppler) and clinical status till 72 hours of life were extracted from electronic medical records.

Continued respiratory support at 4 weeks of age (RS4), was defined as need for invasive ventilation, continuous positive airway pressure, or high-flow nasal cannula at and beyond 4 weeks' postnatal age, whether it be for bronchopulmonary dysplasia defined as need for supplemental oxygen at 36 weeks' postmenstrual age ${ }^{10}$ or apnea. We chose this as an outcome because literature has suggested respiratory factors are strong predictors of hospital stay. This, apart from survival is of interest to the family and the treating team as well.

As this was a retrospective study where deidentified information from electronic medical records were obtained, we did not seek ethical clearance.

Statistical analysis was done using Statistical Package for the Social Sciences (SPSS 20). Univariate analysis was conducted by Fisher's exact test. A $p$-value of $<0.05$ was considered statistically significant. Multivariate analysis on those factors which were significant was conducted.

\section{Results}

Out of total 61 babies born at $<1,000 \mathrm{~g}$ birth weight, 53 were included in the study. Of the others, parents of 4 babies opted for comfort care (born $\leq 24$ weeks of gestation), 2 had major congenital anomalies, and 2 were transferred out to other units before completion of care (-Fig. 1).

Mean birth weight was $781.8( \pm 130.7) \mathrm{g}$ and mean gestational age was $26.4( \pm 1.5)$ weeks ( - Table 1$)$. The smallest baby was $510 \mathrm{~g}$.

Of all the ELBW neonates who received standard care in our unit, $79.2 \%$ survived. Eleven of 53 babies expired (20.7\%) and 25 babies continued to require RS4 (59.5\%). Thirty-five (66\%) neonates suffered composite outcome of death/need for respiratory supports at 4 weeks of life. Nine infants (21.4\%) had bronchopulmonary dysplasia (BPD).

Among all the risk factors analyzed, need for respiratory support with $>0.3$ fraction of inspired oxygen $\left(\mathrm{FiO}_{2}\right)$ beyond 72 hours of life demonstrated strong association with death or RS4. Absence of antenatal steroid and twin pregnancy were also associated significantly with poor outcome. Need

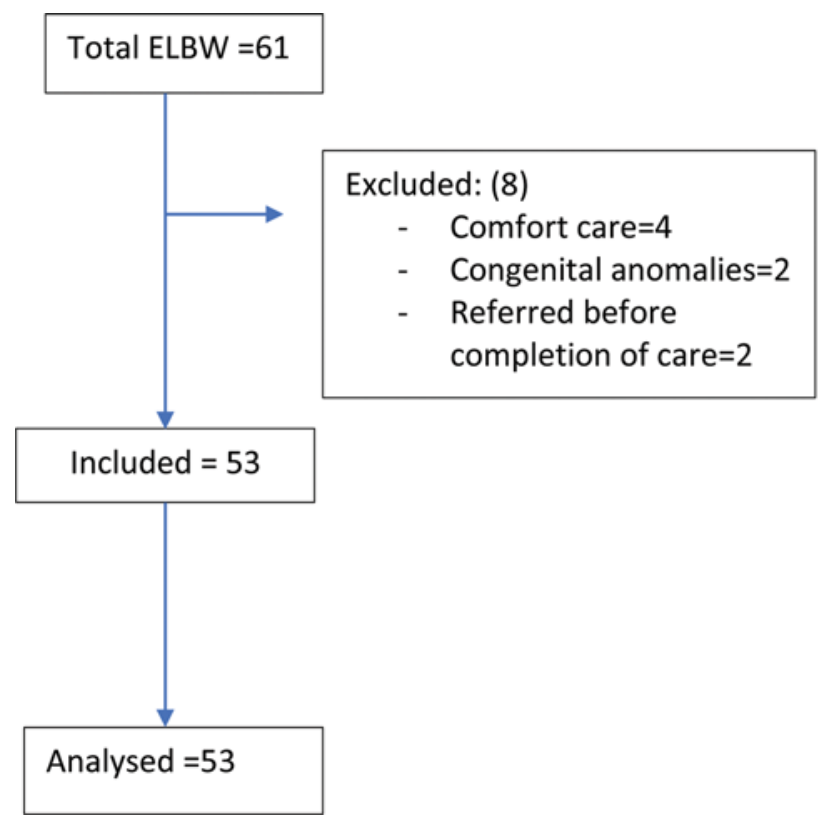

Fig. 1 Study flow diagram. 
Table 1 Baseline characteristics of patients $(n=53)$

\begin{tabular}{|c|c|c|}
\hline $\begin{array}{l}\text { Serial } \\
\text { no. }\end{array}$ & Characteristic & Measure \\
\hline 1 & Birth weight in $\mathrm{g}$, mean (SD) & $781.8( \pm 130.7)$ \\
\hline \multirow[t]{4}{*}{2} & $\begin{array}{l}\text { Distribution according to } \\
\text { birth weight, } n(\%)\end{array}$ & \\
\hline & $500-600 \mathrm{~g}$ & $5(9.4)$ \\
\hline & $600-750 \mathrm{~g}$ & $12(22.6)$ \\
\hline & $>750 \mathrm{~g}$ & $36(67.9)$ \\
\hline 3 & Gestation in wk, mean (SD) & $26.4( \pm 1.5)$ \\
\hline \multirow[t]{4}{*}{4} & $\begin{array}{l}\text { Distribution according to } \\
\text { gestational age in wk, } n(\%)\end{array}$ & \\
\hline & $24-25$ & $14(26.4)$ \\
\hline & $26-28$ & $28(52.8)$ \\
\hline & $\geq 29$ & $11(20.7)$ \\
\hline 5 & Male sex, $n(\%)$ & $23(43.4)$ \\
\hline 6 & $\begin{array}{l}\text { Length of stay of survivors, } \\
\text { in } d \text {, median (IQR) }\end{array}$ & $81(63.5-98)$ \\
\hline 7 & $\begin{array}{l}\text { Postmenstrual age (in wk) of } \\
\text { survivors at discharge, } \\
\text { median (IQR) }\end{array}$ & $38(37-40)$ \\
\hline 8 & $\begin{array}{l}\text { ROP requiring laser } \\
\text { therapy, } n(\%)\end{array}$ & $7(16.6)$ \\
\hline 9 & PVL > Grade 2, n (\%) & $8(15)$ \\
\hline 10 & NEC > Stage 2, n (\%) & $3(7)$ \\
\hline 11 & $\begin{array}{l}\text { PDA requiring medical } \\
\text { treatment, } n(\%)\end{array}$ & $3(7)$ \\
\hline
\end{tabular}

Abbreviations: IQR, interquartile range; NEC, necrotizing enterocolitis; PDA, patent ductus arteriosus; PVL, periventricular leukomalacia; ROP, retinopathy of prematurity; SD, standard deviation.

for $\geq$ two doses of surfactant therapy demonstrated association but was not statistically significant ( $\mathbf{-}$ Table $\mathbf{2}$ ).

Need for chest compression and shock requiring inotropes were strongly associated with mortality ( - Table 3 ). Among other, the early postnatal factors studied, including air leak, need for $>0.3 \mathrm{FiO}_{2}$ beyond 72 hours of life, probable/proven sepsis, feed attained less than $30 \mathrm{~mL} / \mathrm{kg} /$ day at 72 hours, and hemodynamically significant patent ductus arteriosus, were significantly associated with mortality.

From our analysis, need for $>0.3 \mathrm{FiO}_{2}$ beyond 72 hours is significantly associated with death, need for respiratory supports beyond 4 weeks ( - Table 4 ), as well as composite of the above two outcomes.

By multivariate analysis, we found multiple pregnancy $(p=0.015)$, no antenatal steroids $(p=0.011)$, and continued need for $>0.3 \mathrm{FiO}_{2}$ beyond 72 hours $(p=0.000)$ were independently and significantly associated with composite outcome of death or RS4.

\section{Discussion}

Birth of an extreme preterm baby most often comes as a bolt from the blue. In our practice, we resuscitate all live born
Table 2 Association of risk factors with composite outcomedeath or RS4

\begin{tabular}{|c|c|c|c|c|}
\hline $\begin{array}{l}\text { Serial } \\
\text { no. }\end{array}$ & Risk factors & $\begin{array}{l}\text { Composite } \\
\text { outcome, } \\
n(\%)\end{array}$ & OR (Cl) & $p$-Value \\
\hline \multirow[t]{3}{*}{1} & Birth weight & & \multirow[t]{3}{*}{$3.3(0.8-13)$} & \multirow[t]{3}{*}{0.09} \\
\hline & $510-750 \mathrm{~g}$ & $14(82.4)$ & & \\
\hline & $750-999 \mathrm{~g}$ & $21(58.3)$ & & \\
\hline \multirow[t]{3}{*}{2} & Gestation & & \multirow{3}{*}{$\begin{array}{l}4.17 \\
(0.8-21.2)\end{array}$} & \multirow[t]{3}{*}{0.08} \\
\hline & $24-25$ wk & $12(85.7)$ & & \\
\hline & $>25 \mathrm{wk}$ & $23(58.9)$ & & \\
\hline 3 & Plural pregnancy & $20(83.3)$ & $4.6(1.2-17)$ & 0.02 \\
\hline 4 & $\begin{array}{l}\text { No antenatal } \\
\text { steroids }\end{array}$ & 16 (88.9) & $\begin{array}{l}6.7 \\
(1.3-33.3)\end{array}$ & 0.02 \\
\hline 5 & Chorioamnionitis & $3(75)$ & $\begin{array}{l}1.5 \\
(0.15-16.6)\end{array}$ & 1.00 \\
\hline 6 & $\begin{array}{l}\text { Abnormal } \\
\text { Doppler }\end{array}$ & $5(50)$ & $\begin{array}{l}0.43 \\
(0.12-1.7)\end{array}$ & 0.27 \\
\hline 7 & Male sex & $16(69.6)$ & $\begin{array}{l}1.3 \\
(0.41-4.2)\end{array}$ & 0.77 \\
\hline 8 & $\begin{array}{l}\text { Need for chest } \\
\text { compression } \\
\text { at birth }\end{array}$ & $4(100)$ & $\begin{array}{l}5.2 \\
(0.2-103)\end{array}$ & 0.28 \\
\hline 9 & $\begin{array}{l}\text { Surfactant } \\
\geq 2 \text { doses }\end{array}$ & $15(83.3)$ & $\begin{array}{l}3.7 \\
(0.9-15.4)\end{array}$ & 0.07 \\
\hline 10 & $\begin{array}{l}\text { Need for } \\
\text { high-frequency } \\
\text { ventilation }\end{array}$ & $8(80)$ & $\begin{array}{l}2.3 \\
(0.44-12.5)\end{array}$ & 0.46 \\
\hline 11 & Air leak & $2(100)$ & $2.7(0.1-60)$ & 0.54 \\
\hline 12 & $\begin{array}{l}\text { Pulmonary } \\
\text { hemorrhage }\end{array}$ & $4(100)$ & $\begin{array}{l}5.2 \\
(0.2-103.8)\end{array}$ & 0.28 \\
\hline 13 & $\begin{array}{l}\text { Need for } \\
>0.3 \mathrm{FiO}_{2} \\
\text { beyond } 72 \mathrm{~h} \\
\text { of life }\end{array}$ & $23(88.5)$ & $\begin{array}{l}14.3 \\
(3.2-63.0)\end{array}$ & $<0.01$ \\
\hline 14 & $\begin{array}{l}\text { Shock needing } \\
\text { inotropes }\end{array}$ & $8(80)$ & $\begin{array}{l}2.4 \\
(0.4-13.1)\end{array}$ & 0.46 \\
\hline 15 & $\begin{array}{l}\text { Probable or } \\
\text { proven sepsis }\end{array}$ & $7(63.6)$ & $\begin{array}{l}0.9 \\
(0.2-3.6)\end{array}$ & 1.00 \\
\hline 16 & $\begin{array}{l}\text { Feed attained } \\
<30 \mathrm{~mL} / \mathrm{kg} / \text { day }\end{array}$ & $21(72.4)$ & $\begin{array}{l}2.3 \\
(0.7-7.7)\end{array}$ & 0.23 \\
\hline 17 & hsPDA & 5 (45.5\%) & $\begin{array}{l}0.38 \\
(0.09-1.5)\end{array}$ & 0.17 \\
\hline
\end{tabular}

Abbreviations: $\mathrm{Cl}$, confidence interval; $\mathrm{FiO}_{2}$, fraction of inspired oxygen; hsPDA, hemodynamically significant patent ductus arteriosus; OR, odds ratio; RS4, respiratory support at 4 weeks of life separately.

Note: $P$ value $<0.05$ are statistically significant.

infants $>23$ weeks' gestation. Recommendations vary on the guidelines for resuscitation of a neonate at thresholds of viability. The European Resuscitation Council recommend that local survival and outcomes must be taken into consideration. ${ }^{11}$ The 2017 consensus of American College of Obstetricians and Gynecologists recommended antenatal steroids and magnesium sulfate from 24 weeks, and to consider neonatal resuscitation from 22 weeks onwards. ${ }^{4}$

We encourage parents to give their baby a chance and take decisions about withholding escalation of life supports only after 72 hours of intensive care, rather than decide before or 
Table 3 Association of risk factors with mortality

\begin{tabular}{|c|c|c|c|c|}
\hline Serial no. & Risk factors & Mortality, $n(\%)$ & OR (Cl) & $p$-Value \\
\hline 1 & $\begin{array}{l}\text { Birth weight } \\
<750 \mathrm{~g} \\
750-999 \mathrm{~g}\end{array}$ & $7(38.8)$ & $4.9(1.2-20.1)$ & 0.02 \\
\hline \multirow[t]{3}{*}{2} & Gestation & & \multirow[t]{3}{*}{$1.8(0.44-7.5)$} & \multirow[t]{3}{*}{0.40} \\
\hline & $24-25 w k$ & $4 / 14(28.5)$ & & \\
\hline & $>25 \mathrm{wk}$ & $7 / 39(15.9)$ & & \\
\hline 3 & Plural pregnancy & $6(25)$ & $1.6(0.4-7.5)$ & 0.51 \\
\hline 4 & No antenatal steroids & $7(38.8)$ & $4.9(1.2-28.2)$ & 0.02 \\
\hline 5 & Chorioamnionitis & $2(50)$ & $4.44(0.55-35.9)$ & 0.18 \\
\hline 6 & Abnormal Doppler & $2(20)$ & $0.94(0.17-5.24)$ & 1.00 \\
\hline 7 & Male sex & $4(17)$ & $0.69(0.17-2.72)$ & 0.73 \\
\hline 8 & Need for chest compression at birth & $3(75)$ & $15.3(1.4-167.2)$ & 0.03 \\
\hline 9 & Surfactant $\geq 2$ doses & $5(27.7)$ & $1.85(0.4-7.2)$ & 0.47 \\
\hline 10 & Need for high-frequency ventilation & $4(40)$ & $3.42(0.76-15.3)$ & 0.18 \\
\hline 11 & Air leak & $2(100)$ & $5.6(3.1-10.25)$ & 0.04 \\
\hline 12 & Pulmonary hemorrhage & $1(25)$ & $1.3(0.12-13.8)$ & 1.00 \\
\hline 13 & Need for $>0.3 \mathrm{FiO}_{2}$ beyond $72 \mathrm{~h}$ of life & $5 / 26(19.2)^{a}$ & $2.5(0.43-14.5)$ & $<0.01$ \\
\hline 14 & Shock needing inotropes & $6(60)$ & $14.2(2.7-72.8)$ & $<0.01$ \\
\hline 15 & Probable or proven sepsis & $4(36.6)$ & $3.3(0.7-14.9)$ & 0.04 \\
\hline 15 & Feed attained $<30 \mathrm{~mL} / \mathrm{kg} /$ day at $72 \mathrm{~h}$ & $7(24.1)$ & $0.45(0.15-1.3)$ & $<0.01$ \\
\hline 17 & hsPDA & $5(50)$ & $1.33(0.12-12.4)$ & $<0.01$ \\
\hline
\end{tabular}

Abbreviations: $\mathrm{Cl}$, confidence interval; $\mathrm{FiO}_{2}$, fraction of inspired oxygen; hsPDA, hemodynamically significant patent ductus arteriosus; OR, odds ratio. ${ }^{\mathrm{a}}$ Four deaths before 72 hours excluded from denominator.

Note: $P$ value $<0.05$ are statistically significant.

Table 4 Association of risk factors with need for respiratory supports at 4 weeks (RS4)

\begin{tabular}{|c|c|c|c|c|}
\hline Serial no. & Risk factors & $\mathrm{RS} 4, n(\%)$ & $\mathrm{OR}(\mathrm{Cl})$ & $p$-Value \\
\hline 1 & $\begin{array}{l}\text { Birth weight } \\
<750 \mathrm{~g} \\
750-999 \mathrm{~g}\end{array}$ & $8(72.7)$ & $2.5(0.55-11.2)$ & 0.23 \\
\hline \multirow[t]{3}{*}{2} & Gestation & & \multirow[t]{3}{*}{$4(0.7-21.8)$} & \multirow[t]{3}{*}{0.1} \\
\hline & $24-25 w$ & $8 / 10(80)$ & & \\
\hline & $>25 w$ & $16 / 32(50)$ & & \\
\hline 3 & Plural pregnancy & $14(77.7)$ & $4.9(1.2-19.3)$ & 0.03 \\
\hline 4 & No antenatal steroids & $9(81.8)$ & $4.8(0.89-25.9)$ & 0.08 \\
\hline 5 & Chorioamnionitis & $1(50)$ & $0.73(0.04-12.6)$ & 1.00 \\
\hline 6 & Abnormal Doppler & $3(37.5)$ & $0.37(0.07-1.82)$ & 0.25 \\
\hline 7 & Male sex & $12(63.1)$ & $1.57(0.45-5.4)$ & 0.54 \\
\hline 8 & Need for chest compression at birth & $1(100)$ & $1.78(1.36-2.33)$ & 1.00 \\
\hline 9 & Surfactant $\geq 2$ doses & $10(76.9)$ & $3.57(0.81-15.7)$ & 0.10 \\
\hline 10 & Need for high-frequency ventilation & $4(66.6)$ & $1.6(0.25-9.87)$ & 0.68 \\
\hline 11 & Air leak & 0 & - & - \\
\hline 12 & Pulmonary hemorrhage & $3(100)$ & $1.85(1.38-2.48)$ & 0.24 \\
\hline 13 & Need for ventilation beyond $72 \mathrm{~h}$ of life & $18(85.7)$ & $15(3.1-70.3)$ & $<0.01$ \\
\hline 14 & Shock needing inotropes & $2(50)$ & $0.7(0.09-5.7)$ & 1.00 \\
\hline 15 & Probable or proven sepsis & $3(42.8)$ & $0.5(0.09-2.58)$ & 0.43 \\
\hline 16 & Feed attained $<30 \mathrm{~mL} / \mathrm{kg} /$ day & $14(63.6)$ & $1.75(0.5-6.0)$ & 0.53 \\
\hline 17 & hsPDA & $4(80)$ & $3.4(0.34-33.3)$ & 0.37 \\
\hline
\end{tabular}

Abbreviations: $\mathrm{Cl}$, confidence interval; hsPDA, hemodynamically significant patent ductus arteriosus; OR, odds ratio.

Note: $P$ value $<0.05$ are statistically significant. 
immediately after birth. We resuscitate at the earnest, and offer standard care, discuss repeatedly with the family, and take the decisions on no escalation of therapy only if the situation appears futile even after 72 hours. However, the anxiety of parents to know what is expected in the coming days cannot be overemphasized. Instead of making survival predictions immediately after birth, ${ }^{1,2}$ deferring meaningful predictions to a few days after birth helps the intensivist to provide standard care for a reasonable amount of time and assess the response to supports. It also permits the parents time to cope with the situation. A stepwise approach has been previously described where decisions may be reconsidered based on evolution of clinical condition. ${ }^{4}$

We planned this study to analyze association of risk factors both perinatal as well in the early neonatal period (within 72 hours of life) with the two most crucial immediate outcomes-mortality and continued need for respiratory supports at 4 weeks of age (RS4). We chose RS4 as an outcome instead of the current definition of BPD. ${ }^{11}$ Four weeks of support itself poses a strain on unit resource utilization. ${ }^{5}$ In India, this emotionally and financially drains the family.

Of the 53 ELBW infants studied in our cohort, 42 (79.2\%) survived till discharge. Tagare et al reported 56\% survival among ELBW neonates from a Level III neonatal unit in India. ${ }^{12}$ Narayan et al observed $49 \%$ survival in ELBW. ${ }^{13}$ Our results are comparable to reports from the developed world. $^{14}$

Perinatal risk factors have been extensively studied as predictors. ${ }^{1,2}$ These have the distinct disadvantage of deducing very early prognostications. Authors have reported risk factors associated with mortality. Lower birth weight and gestational age, asphyxia, air leak syndrome, sclerema, seizures, and acute renal failure have been found to be significantly associated with mortality. ${ }^{12,13}$ But these studies have not reported any timelines. These morbidities can occur anytime during hospital stay. Moreover, we report survival of nearly $80 \%$ in ELBW, this is better representative of current improved state of intensive care in India. We found some of the significant predictors like lower birth weight and air leak to be similar to the above studies. Surprisingly, we did not find gestational age as a significant predictor.

In the EPIBEL study, ${ }^{15}$ outcomes of the smallest of babiesextremely preterm infants less than 26 weeks-were reported. Vaginal delivery, shorter gestation, air leak, longer ventilator dependence, and higher initial oxygen need were independently associated with death. Among the survivors, $63 \%$ had adverse outcomes like chronic lung disease at 36 weeks' postmenstrual age. ${ }^{16}$ Mukhopadhyay et al reported that low birth weight, lack of antenatal steroids, birth asphyxia, ventilation, and duration of oxygen therapy were predictors for major morbidity. ${ }^{16}$ Many of these reflect merely the severity of disease and the associations are expected; we have attempted to predict morbidity based on factors much earlier on (within 72 hours), so that parents may be appropriately counseled and prepared. Continued need for $>0.3 \mathrm{FiO}_{2}$ at 72 hours of life predicted both mortality as well as RS4.
In resource-limited settings, it is essential to strike a balance between very early predictions with waiting too long.

We studied the smallest babies where predictions and parental preparation are an essential part of clinical care. We could demonstrate that sick clinical status in the first 72 hours was often an augury to death or need for longer intensive care. We, however, understand the inherent limitations of a retrospective study.

\section{Conclusion}

Need for respiratory supports with $\mathrm{FiO}_{2}>0.3$ beyond 72 hours of life, multiple pregnancy, and absence of antenatal steroid were significantly and independently associated with either mortality or requirement for respiratory supports at 4 weeks of age. Chest compression at birth and need for inotropes are strong predictors of mortality in ELBW; continued need for respiratory support at 72 hours with more than $0.3 \mathrm{FiO}_{2}$ predicted prolonged respiratory support.

There seems to be cogent reason to be forthcoming and inform the family of possible long needs for intensive care or poor outcome when the infant remains on $>0.3 \mathrm{FiO}_{2}$ at and beyond 72 hours. Regional data should guide care plans to benefit parents and health planners.

\section{Funding \\ None.}

\section{Conflict of Interest}

None declared.

\section{References}

1 Ge WJ, Mirea L, Yang J, Bassil KL, Lee SK, Shah PS; Canadian Neonatal Network. Prediction of neonatal outcomes in extremely preterm neonates. Pediatrics 2013;132(04):e876-e885

2 Li Y, Yan J, Li M, et al. Addition of SNAP to perinatal risk factors improves the prediction of bronchopulmonary dysplasia or death in critically ill preterm infants. BMC Pediatr 2013;13:138

3 Nimbalkar SM, Bansal SC. Periviable birth - the ethical conundrum. Indian Pediatr 2019;56(01):13-17

4 American College of Obstetricians and Gynecologists; Society for Maternal-Fetal Medicine. Obstetric Care consensus No. 6: periviable birth. Obstet Gynecol 2017;130(04):e187-e199

5 Shiao S-YPK, Andrews CM, Ahn C. Ventilatory support and predictors of hospital stay in neonates. Newborn Infant Nurs Rev 2003;3(04):166-172

6 Pleasure J, Gennaro S, Cnaan A, Wolf F. An expanded neonatal morbidity scale for premature infants. J Nurs Meas 1997;5(02): 119-138

7 Ballard JL, Khoury JC, Wedig K, Wang L, Eilers-Walsman BL, Lipp R. New Ballard score, expanded to include extremely premature infants. J Pediatr 1991;119(03):417-423

8 Textbook of Neonatal Resuscitation (NRP). 7th Ed. United States of America: GM Weiner; 2016:225-242

9 Sweet DG, Carnielli V, Greisen G, et al. European Consensus Guidelines on the Management of Respiratory Distress Syndrome - 2019 update. Neonatology 2019;115(04):432-450

10 Davidson LM, Berkelhamer SK. Bronchopulmonary dysplasia: chronic lung disease of infancy and long-term pulmonary outcomes. J Clin Med 2017;6(01):4 
11 Wyllie J, Bruinenberg J, Roehr CC, Rüdiger M, Trevisanuto D, Urlesberger B. European Resuscitation Council Guidelines for Resuscitation 2015: Section 7. Resuscitation and support of transition of babies at birth. Resuscitation 2015;95:249-263

12 Tagare A, Chaudhari S, Kadam S, Vaidya U, Pandit A, Sayyad MG. Mortality and morbidity in extremely low birth weight (ELBW) infants in a neonatal intensive care unit. Indian J Pediatr 2013;80 (01):16-20

13 Narayan S, Aggarwal R, Upadhyay A, Deorari AK, Singh M, Paul VK. Survival and morbidity in extremely low birth weight (ELBW) infants. Indian Pediatr 2003;40(02):130-135
14 Bassler D, Stoll BJ, Schmidt B, et al; Trial of Indomethacin Prophylaxis in Preterms Investigators. Using a count of neonatal morbidities to predict poor outcome in extremely low birth weight infants: added role of neonatal infection. Pediatrics 2009;123(01):313-318

15 Vanhaesebrouck P, Allegaert K, Bottu J, et al; Extremely Preterm Infants in Belgium Study Group. The EPIBEL study: outcomes to discharge from hospital for extremely preterm infants in Belgium. Pediatrics 2004;114(03):663-675

16 Mukhopadhyay K, Louis D, Mahajan R, Kumar P. Predictors of mortality and major morbidities in extremely low birth weight neonates. Indian Pediatr 2013;50(12):1119-1123 